\title{
HMM Based Cough Sound Scrutiny for Classification of Asthma and Pneumonia in Paediatry
}

\author{
T.Manoj Prasath, Vasukidevi Ramachandran, S.Geetha, R.Vasuki
}

\begin{abstract}
Isolating pediatric asthma from pediatric pneumonia is one of the serious issues in remote territories. These sicknesses have covering side effects, however require radically extraordinary medicines. Existing rules for pneumonia order in asset poor areas from The World Health Organization require the utilization of bronchodilator test to isolate asthma from pneumonia. In any case, bronchodilator is a costly test to direct and not effectively accessible in remote regions. In this investigation, we star represent an imaginative and novel system utilizing hack sound examination to isolate pneumonia cases from asthma. In crafted by this paper we dissected hack sound information from 20 subjects (10 pneumonia and 10 asthma patients). Utilizing scientific highlights of hack sounds, a HMM classifier was prepared to distinguish pneumonic hack and asthmatic hack. At that point by registering Pneumonic Cough Index every patient was delegated either into pneumonia or asthma. Proposed strategy accomplished a precision of $90 \%$ $($ affectability $=100 \%$ and explicitness $=80 \%)$ in arranging pneumonia and asthma patients. Our outcomes demonstrate that hack sound convey basic data which can be utilized to isolate asthma patients from pneumonia. Proposed strategy in this paper indicates potential to turn into an option for bronchodilator test in the asset poor zones of the world.
\end{abstract}

Keywords-Paediatric, pneumonia, asthma, bronchodilator, Cough, hidden- markov model.

\section{INTRODUCTION}

Pneumonia is one of the perilous ailments for kids. In 2015 , it guaranteed in excess of nine hundred thousand passings in kids under five years . In comparable, asthma is the most widely recognized incessant infection in youth. The commonness of asthma in creating nations it ranges from $4 \%$ to $32 \%$ wherein dominant part of passings happened in low to center pay nations[1-5].

Individuals in low pay nations, they have restricted access to present day analysis instruments. To help the determination of genuine sicknesses, for example, pneumonia/asthma in such districts[6-9], The WHO have built up an essential rule called the Integrated Management of Childhood Illness (IMCI) . As per the rule, the clinical indications of hack and additionally trouble of breathing are

Revised Manuscript Received on July 10, 2019

T.Manoj Prasath, Assistant Professor, Department of Biomedical Engineering, Bharath Institute of Higher Education and Research, Chennai600073 T.N,India.

Dr.Vasukidevi Ramachandran, Assistant Professor, Department of Biomedical Engineering, Bharath Institute of Higher Education and Research, Chennai-600073 T.N,India.

S.Geetha, Assistant Professor, Department of Biomedical Engineering, Bharath Institute of Higher Education and Research, Chennai-600073 T.N,India. Engineering, Bharath Institute of Higher Education and Research, Chennai600073 T.N.India.
Dr.R.Vasuki, Assistant Professor, Department of Biomedical

the screening in measure for pneumonia. Quick breathing rate is a determinant of whether pneumonia exists. The determination of asthma is built up by the side effects of wheezing (regularly with hack), quick breathing, hyperventilation of the lungs, chest divider in-drawing and delayed termination.

The IMCI algorithm for pneumonia diagnosis has high sensitivity $(69-94 \%)$ but at the cost of poor specificity (67$16 \%)$. Hence, IMCI leads to a high false positive rate[1016]. One major reason for high false positive rate is the overlap in the symptoms of pneumonia and asthma in the IMCI. Two recent studies on IMCI implementation in Uganda and India showed that many asthma cases were misdiagnosed as pneumonia and received medication meant for pneumonia. To address this issue, the WHO recommends a bronchodilator test in children with wheeze and fast breathing and/or lower chest in-drawing before they are classified as having pneumonia [17-21]. If the symptoms disappear after the bronchodilator test the treatment is continued; otherwise antibiotic is prescribed. However, the issue is bronchodilators and their delivery systems such as inhalers or nebulizers are expensive. They are also rare in resource-limited settings. Further, extra efforts to sterilize the bronchodilator delivery system are required to avoid the spread of infections.

In this paper, we propose a cough sound analysis method as an alternative for bronchodilator test in remote areas. Cough is a major symptom of both pneumonia and asthma. It is well known that cough sounds carry information related to respiratory diseases . One study claimed that quantitative cough analysis can differentiate healthy, asthmatic, and COPD (chronic obstruction pulmonary diseases) subjects with an accuracy of $85-90 \%$. Our own feasibility studied indicated that cough carries vital information that can be extracted by quantitative analysis and used to screen pneumonia in remote regions[30-35].

We hypothesize that cough sounds carry vital information specific to pneumonia and asthma diseases. Support for this hypothesis comes from the Path physiology of pneumonia and asthma, the physics of cough sound generation, and our prior explorations. The outcome of this work has the potential to transform the way the pneumonia/asthma is man-aged in remote resource-limited settings of the world[36-45].

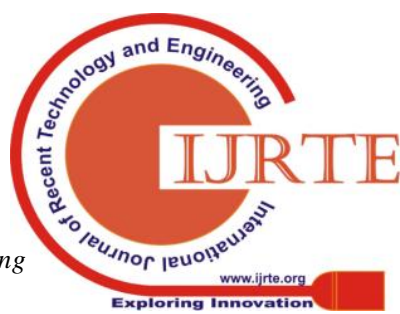




\section{HMM BASED COUGH SOUND SCRUTINY FOR CLASSIFICATION OF ASTHMA AND PNEUMONIA IN PAEDIATRY}

\section{MATERIALS AND METHODOLOGY:}

\section{A. Information procurement}

The consideration criteria for this examination are hack, shortness of breath, fever (temperature $\geq 37.5^{\circ} \mathrm{C}$ ). Patients with no less than two of the side effects were incorporated. Patients with cutting edge sicknesses, for example, malignant growth, bead safety measures (tuberculosis) or patients with non-obtrusive ventilation were rejected from this investigation[22-29].

The account setup comprised of a couple of low-clamor receivers (Model NT3, RODE®, Sydney, Australia), a preenhancer and an A/D converter (Model Mobile Pre-USB, M-Audio $\AA$, CA, USA). The inspecting rate was set at Fs = $44.1 \mathrm{k}$ tests/s at 16-bits/test. The separation between the patients and the mouthpiece pointed towards them fluctuated between $40 \mathrm{~cm}-70 \mathrm{~cm}$ relying upon the situation of their heads.

\section{B. Informational index planning}

In this investigation, we included $\mathrm{W}=20$ pediatric patients analyzed as pneumonia or asthma. To develop the dataset, the initial 50 clean hack sounds from each stable account were chosen for examination. In the event that the quantity of hacks in an account were under 50, at that point all hacks satisfying the criteria were utilized. Let DS speaks to the complete number of hacks acquired from 20 patients.

\section{Arrangement of pneumonia and asthma}

The strategy to isolate pneumonia and asthma subjects is a two-advance procedure which is depicted beneath.

Stage 1 - In this stage a classifier was prepared to naturally mark each hack as either 'pneumonic hack' or 'asthmatic hack'. For this, each hack occasion is divided utilizing a rectangular window of length $\mathrm{N}$ ms . To examine the ideal size of rectangular window, $\mathrm{N}$ was changed from $20 \mathrm{~ms}$ to $60 \mathrm{~ms}$ in ventures of $10 \mathrm{~ms}$, with half cover. From each section, Mel-Frequency Cepstral Coefficients (MFCC) were processed to shape a numerical component vector. The MFCCs are ghostly highlights which approximates the sound-related framework conduct by utilizing non-straight recurrence scale. They have been discovered valuable in portrays the transient normal for hack scenes. Next, utilizing scientific highlights a programmed example classifier was prepared to name each hack occasion. In this paper we utilized a classifier. A HMM classifier mod-els the probabilistic conduct of the MFCCs includes in the hack scenes. To display the probabilistic attributes of highlight vector, multivariate Gaussian Mixture Model (GMM) with j segments was utilized. To locate the ideal estimation of $\mathrm{j}$, HMM were structured with $\mathrm{j}=[1,2,4,6])$. Distinctive arrangements of HMM were intended for pneumonia hacks and asthma hacks. Yield of a HMM show is a LogLikelihood (LL) score. The higher the LL, higher is the likelihood of hack having a place with that demonstrate. A hack was named as 'pneumonic hack' if LL score of the pneumonia HMM was higher than

\section{LL score of the asthma HMM.}

Stage 2 - Once all the hack occasions are named as either' pneumonia hack' or 'asthmatic hack', following strategy in discourse just as hack preparing. In this work MFCCs

stage 1, we processed Pneumonic Cough Index (PCI) . Give $\mathrm{Q}$ a chance to be the quantity of hacks named pneumonia and $\mathrm{T}$ is the all out number of hacks broke down from a subject. The PCI is figured as given in .

$\mathrm{PCI}=\mathrm{Q} / \mathrm{T}$

Subjects that have PCI higher than the ideal PCI edge $(\gamma)$ are delegated pneumonia else as asthma. To figure the ideal $\gamma$ we utilized Receiver-Operating-Characteristic bend.

\section{Approval technique and Performance Valuation}

We utilized Leave One out Validation (LOV) system to approve the technique. The LOV system includes utilizing information from every one of the patients with the exception of one to prepare the model and information from the rejected patient to approve the strategy. This procedure is methodicallly rehashed with the end goal that information from each subject in the dataset is utilized as the approval information precisely one time. To assess the execution of the structured models, execution estimates, for example, Sensitivity, Specificity, Accuracy, Positive Predicted Value, Negative Predicted Value, Cohen's Kappa measurement were figured.

\section{RESULTS AND DISCUSSION:}

Dataset and clinical discoveries Our examination dataset comprises of $\mathrm{W}=20$ subjects, with eight guys and twelve females. The age extend was one to eighteen months (mean twenty-five months). The proportion of pneumonia to asthma subjects was $1: 1$. The complete number of hacks in the informational collection DS was 738 , with 461 hacks from pneumonia subjects and 277 hacks from asthma subjects. Over an hour of period, the normal number of hacks in pneumonia subjects was bigger (48 hacks) than that in asthma subjects (28 hacks).

\section{FUTURE WORK :}

In future work it is intriguing to get hack sounds from the pneumonia and asthma patients. As we gather the hack sound from the patients, those sounds are given as a contribution to the program we have created in MATLAB. By creating Hidden Morkov Model as an analyser in the program two windows are produced for the asthma and pneumonia each. With this program the new hack sound will be naturally distinguished.

\section{REFERENCES :}

1. J. Saunders: $\backslash$ Real-Time Discrimination of Broadcast Speech/Music", Proc. ICASSP'96, vol.II, pp.993-996, Atlanta, May, 1996

2. E. Scheirer, M. Slaney: IConstruction and Evaluation of a Robust Multifeature Speech/Music Discriminator", Proc. ICASSP'97, Munich, Germany, April, 1997

3. L. Wyse, S. Smoliar: \Toward Content-based Audio Indexing and Retrieval and a New Speaker Discrimination Technique", downloaded from http://www.iss.nus.sg/People/lwyse/lwyse.html, Institute of Systems Science, National Univ. of Singapore, Dec., 1995 
4. D. Kimber, L. Wilcox: \Acoustic Segmentation for Audio Browsers", Proc. Interface Conference, Sydney, Australia, July, 1996

5. A. Ghias, J. Logan, D. Chamberlin: \Query By Humming Musical Information Retrieval in An Audio Database", Proc. ACM Multimedia Conference, pp.231-235, Anaheim, CA, 1995

6. J. Foote: IContent-Based Retrieval of Music and Audio", Proc. SPIE'97, Dallas, 1997

7. E. Wold, T. Blum, D. Keislar, et al.: IContent-Based Classification, Search, and Retrieval of Audio", IEEE Multimedia, pp.27-36, Fall, 1996

8. Z. Liu, J. Huang, Y. Wang, et al.: \Audio Feature Extraction and Analysis for Scene Classification", Proc. of IEEE 1st Multimedia Workshop, 1997

9. N. Patel, I. Sethi: \Audio Characterization for Video Indexing", Proc. SPIE on Storage and Retrieval for Still Image and Video Databases, Vol.2670, pp.373-384, San Jose, 1996

10. T. Zhang, C.-C. Kuo: IContent-based Classi fication and Retrieval of Audio", SPIE's 43rd Annual Meeting Conference on Advanced Signal Processing Algorithms, Architectures, and Implementations VIII, San Diego, July 1998

11. E. Miyasaka: \Timbre of Complex Tone Bursts with Time Varying Spectral Envelope", Proceedings of ICASSP'82, Vol.3, pp.1462-5, Paris, May 1982

12. F. Everest: The Master Handbook of Acoustics, McGraw-Hill, Inc., 1994

13. D. Reynolds, R. Rose: IRobust Text-Independent Speaker Identification Using Gaussian Mixture Speaker Models", IEEE Transactions on Speech and Audio Processing, Vol.3, No.1, pp.72-83, 1995

14. L. Rabinar, B. Juang: Fundamentals of Speech Recognition, Prentice-Hall, Inc., New Jersey, 1993

15. S. Bow: Pattern Recognition, Marcel Dekker, Inc., 1984

16. Sharmila S., Jeyanthi Rebecca L., Das M.P.,Production of Biodiesel from Chaetomorpha antennina and Gracilaria corticata,Journal of Chemical and Pharmaceutical Research,V-4,I-11,PP-4870-4874,Y-2012

17. Aarthi C., Ramesh Babu P.B.,Anti-cancer activity of Phyllanthus reticulatus on colon cancer cell line, International Journal of Civil Engineering and Technology,V-8,I-1,PP-943947,Y-2017

18. Sharmila S., Jeyanthi Rebecca L., Das M.P., Saduzzaman M.,Isolation and partial purification of protease from plant leaves,Journal of Chemical and Pharmaceutical Research,V4,I-8,PP-3808-3812,Y-2012

19. Jayalakshmi T., Krishnamoorthy P., Ramesh Babu P.B., Vidhya B.,Production, purification and Biochemical characterization of alkaline Fibrinolytic enzyme from Bacillus subtilisstrain-GBRC1,Journal of Chemical and Pharmaceutical Research,V-4,I-12,PP-5027-5031,Y-2012

20. Jeyanthi Rebecca L., Susithra G., Sharmila S., Das M.P.,Isolation and screening of chitinase producing Serratia marcescens from soil,Journal of Chemical and Pharmaceutical Research,V-5,I-2,PP-192-195,Y-2013

21. Aarthi C., Ramesh Babu P.B.,Antimicrobial and antioxidant activity of phyllanthus niruri,International Journal of Pharmacy and Technology,V-8,I-2,PP-14701-14707,Y-2016

22. Anbuselvi S., Jeyanthi Rebecca L., Sathish Kumar M., Senthilvelan T.,GC-MS study of phytochemicals in black gram using two different organic manures,Journal of Chemical and Pharmaceutical Research,V-4,I-2,PP-1246$1250, \mathrm{Y}-2012$

23. Soniyapriyadharishni A.K., Ramesh Babu P.B.,Data mining strategies for identification of HNF4A MODY gene using gene prioritize tool,Journal of Chemical and Pharmaceutical Research,V-6,I-3,PP-1126-1133,Y-2014

24. Sharmila S., Jeyanthi Rebecca L., Naveen Chandran P., Kowsalya E., Dutta H., Ray S., Kripanand N.R.,Extraction of biofuel from seaweed and analyse its engine performance,International Journal of Pharmacy and Technology, V-7,I-2,PP-8870-8875,Y-2015

25. Sharmila S., Jeyanthi Rebecca L., Saduzzaman M.,Biodegradation of domestic effluent using different solvent extracts of Murraya koenigii,Journal of Chemical and Pharmaceutical Research,V-5,I-2,PP-279-282,Y-2013

26. Jeyanthi Rebecca L., Sharmila S., Das M.P., Seshiah C.,Extraction and purification of carotenoids from vegetables,Journal of Chemical and Pharmaceutical Research,V-6,I-4,PP-594-598,Y-2014

27. Krishnamoorthy P., Praveen Kumar P.K., Ramesh Babu P.B.,Community based evaluation of phenylthiocarbamide (PTC) sensitivity and Dermatoglyphics as a genetic marker in Tamilnadu, India,International Journal of Pharmacy and Technology,V-5,I-3,PP-5705-5712,Y-2013

28. Sharmila S., Jeyanthi Rebecca L.,GC-MS Analysis of esters of fatty acid present in biodiesel produced from Cladophora vagabunda,Journal of Chemical and Pharmaceutical Research,V-4,I-11,PP-4883-4887,Y-2012

29. Sinha S., Rajasulochana P., Ramesh Babu P.B., Krishnamoorthy P.,Comparative modelling of shikimate kinase $(\mathrm{M} \mathrm{Tb})$ and molecular docking studies of its known inhibitors, Research Journal of Pharmaceutical, Biological and Chemical Sciences, V-4,I-3,PP-715-720,Y-2013

30. Jeyanthi Rebecca L., Dhanalakshmi V., Sharmila S.,Effect of the extract of Ulva sp on pathogenic microorganisms, Journal of Chemical and Pharmaceutical Research,V-4,I-11,PP-48754878,Y-2012

31. Sharmila S., Jeyanthi Rebecca J.,A comparative study on the degradation of leather industry effluent by Marine algae,International Journal of Pharmaceutical Sciences Review and Research,V-25,I-2,PP-46-50,Y-2014

32. Ramesh Babu P.B., Krishnamoorthy P., Gayathri G.,Identification of drug target site on citrate synthase of food pathogen - Campylobacter jejuni,Research Journal of Pharmaceutical, Biological and Chemical Sciences,V-4,I1,PP-618-623,Y-2013

33. Sharmila S., Rebecca Jeyanthi L., Saduzzaman M.,Biodegradation of tannery effluent using Prosopis juliflora,International Journal of ChemTech Research, V-5,I5,PP-2186-2192,Y-2013

34. Kumar S., Das M.P., Jeyanthi Rebecca L., Sharmila S.,Isolation and identification of LDPE degrading fungi from municipal solid waste,Journal of Chemical and Pharmaceutical Research,V-5,I-3,PP-78-81,Y-2013

35. Das M.P., Jeyanthi Rebecca L., Sharmila S., Anu, Banerjee A., Kumar D.,Identification and optimization of cultural conditions for chitinase production by Bacillus amyloliquefaciens SM3,Journal of Chemical and Pharmaceutical Research,V-4,I-11,PP-4816-4821,Y-2012

36. Ramesh Babu P.B., Krishnamoorthy P., Rekha R.,Develoment of comprehensive online database model for genes responsible for asthma,Research Journal of Pharmaceutical, Biological and Chemical Sciences, V-4,I-1,PP-865-871,Y-2013

37. Devi M., Jeyanthi Rebecca L., Sumathy S.,Bactericidal activity of the lactic acid bacteria Lactobacillus delbreukii,Journal of Chemical and Pharmaceutical Research,V-5,I-2,PP-176-180,Y-2013

38. Ramesh Babu P.B., Miller T.L., Chidekel A., Shaffer T.H.,Clara cell protein mediates secretion of proteins, IL-8 and IL-6 in human airway epithelial cell line Calu-3 exposed to hyperoxia,Journal of Chemical and Pharmaceutical Research,V-4,I-6,PP-3164-3170,Y-2012

39. Bhuvaneswari B., Hari R., Vasuki R., Suguna,Antioxidant and antihepatotoxic activities of ethanolic extract of Solanum torvum,Asian Journal of Pharmaceutical and Clinical Research, V-5,I-SUPPL. 3,PP-147-150,Y-2012 
40. Abraham Samuel F., Mohan V., Jeyanthi Rebecca L.,Physicochemical and heavy metal analysis of sugar mill effluent,Journal of Chemical and Pharmaceutical Research, V6,I-4,PP-585-587,Y-2014

41. Narayani P.C., Anbu J., Vasuki R., Hari R.,Invitro and invivo anti-arthritic activity of combined ethanolic extracts of Calotropis gigantea and Cardiospermum halicacabum in Wistar rats,Journal of Natural Remedies, V-14,I-1,PP-5866,Y-2014

42. Paul Das M., Jeyanthi Rebecca L., Sharmila S., Anu, Banerjee A., Kumar D.,Identification and optimization of cultural conditions for chitinase production by Bacillus amyloliquefaciens SM3,Journal of Chemical and Pharmaceutical Research,V-4,I-12,PP-4969-4974,Y-2012

43. Vasuki R., Hari R., Pandian S., Arumugam G.,Hepatoprotective action of ethanolic extracts of eclipta alba and piper longum linn and their combination on CCL 4 induced hepatotoxicity in rats,International Journal of Pharmacy and Pharmaceutical Sciences, V-4,I-SUPPL.1,PP455-459, Y-2012

44. Saduzaman M., Sharmila S., Jeyanthi Rebecca L.,Efficacy of leaf extract of Moringa oleifera in treating domestic effluent,Journal of Chemical and Pharmaceutical Research,V5,I-2,PP-139-143,Y-2013

45. Senthil Kumar K., Vasuki R., Priya R.,Green synthesis, pegylation of silver nano herbal complexand study of its antimutagenicity activity,International Journal of Pharmacy and Technology, V-8,I-2,PP-12130-12143,Y-2016

46. Srivastava S., Seethalakshmi I., Jeyanthi Rebecca L.,Antimicrobial and antioxidant properties of cissus quandrangularis,Journal of Chemical and Pharmaceutical Research,V-5,I-5,PP-131-134,Y-2013

47. Gireeshan M.G., Vasuki R., Krishnakumar T.,High power production from elephantâ $€^{\mathrm{TM}_{\mathrm{S}}}$ urine, International Journal of Pharmacy and Technology,V-6,I-2,PP-6714-6718,Y-2014

48. Jeyanthi Rebecca L., Dhanalakshmi V., Sharmila S., Das M.P.,In vitro antimicrobial activity of Gracilaria SP and Enteromorpha SP,Research Journal of Pharmaceutical, Biological and Chemical Sciences,V-4,I-1,PP-693-697,Y2013

49. Jeyanthi Rebecca L., Dhanalakshmi V., Thomas T.,A comparison between the effects of three algal extracts against pathogenic bacteria,Journal of Chemical and Pharmaceutical Research,V-4,I-11,PP-4859-4863,Y-2012 